Article

\title{
Heat Transfer Analysis of Timber Windows with Different Wood Species and Anatomical Direction
}

\author{
Namhyuck Ahn ${ }^{1}$ and Sanghoon Park ${ }^{2, *}$ \\ 1 LG Hausys, Science Park, Seoul 07796, Korea; nhahn@lghausys.com \\ 2 Division of Architecture, College of Engineering, Sun Moon University, Chungnam 31460, Korea \\ * Correspondence: sanghoon@sunmoon.ac.kr
}

Received: 20 October 2020; Accepted: 16 November 2020; Published: 19 November 2020

\begin{abstract}
When assessing the hygrothermal performance of timber windows, it is important to apply the unique thermal conductivity of wood by each wood species as well as an anatomical direction within the same material as they affect the performance and long-term durability of products. A series of heat transfer analyses of window frames using THERM and WINDOW along with measurements on the thermal conductivity of five hardwoods using laser flash apparatus (LFA) was performed to compare and evaluate heat transmittance (U-value) and condensation resistance (CR) of three types of timber and hybrid timber windows. For each window type, 6.1 to $10.3 \%$ of the maximum difference in the heat transmittance among cases was calculated. Besides, a linear correlation was found between the U-value and the CR for most cases; thus, the selection of wood species and anatomical direction would improve the hygrothermal performance of timber windows overall. The results also indicated that there were some cases where the overall CR of windows did not improve because the U-value of the glazing system was not sufficiently low.
\end{abstract}

Keywords: timber windows; hybrid timber windows; wood physics; wood anatomy; thermal conductivity; heat transmittance; condensation resistance; hygrothermal performance; heat transfer analysis

\section{Introduction}

\subsection{Background}

Wood has been widely used as a building material since wood is grown throughout the world. Besides using wood as a structural material, it can also be designed for nonstructural elements such as windows, doors, walls, and other finishing elements. With the beauty of wood and cost-effectiveness, timber windows are one of the popular options in the construction industry in North America and Europe [1-3]. Recently, other materials such as aluminum with a thermal break have been integrated into window frames in various ways to reduce the maintenance cost and improve the stiffness of timber windows.

When timber windows are considered for building envelopes, several factors include cost, price, comfort, durability, maintenance, style, integration in building, and others [4]. Those affect the choice of wood species. As laws and restrictions for energy-efficient buildings are unprecedentedly strict, designers and manufacturers are being pushed to develop high-performance building products. With growing attention to energy-efficient buildings such as Passivhaus and nearly zero-energy buildings (nZEBs), it is now essential to consider building materials' thermal properties besides other considerations in designing window frames. 


\subsection{Purpose}

Generally, wood's thermal conductivity is much less than that of other structural building materials [5]. Many factors affect the thermal conductivity of wood: specific gravity and density, grain direction, and moisture content, to name a few [6-8]. Existing research has demonstrated that there could be variations in thermal conductivity according to wood species [9-11]. Extensive research about the calculation of thermal properties of wood has shown that the thermal conductivity of various hardwood species with $12 \%$ moisture content ranges from $0.10 \mathrm{w} / \mathrm{m} \cdot \mathrm{K}$ to $0.21 \mathrm{w} / \mathrm{m} \cdot \mathrm{K}$, whereas that of softwood varies from $0.094 \mathrm{w} / \mathrm{m} \cdot \mathrm{K}$ to $0.17 \mathrm{w} / \mathrm{m} \cdot \mathrm{K}$ (TenWolde and McNatt and Krahn, 1988). According to the 13 tropical hardwood species' thermal conductivity, up to $490 \%$ of the difference for transversal cut samples was found (Aggrey-Smith and Preko and Owusu, 2016). Measurement of three wood species from east-southern Asia and Africa also have shown the maximum difference of $33 \%$ in the longitudinal section (Jankowska and Kazakiewicz, 2014). Due to its anisotropic property, the thermal conductivity of wood differs by its anatomical directions. Conductivity in a longitudinal direction (along the grain) is measured as more than two times the conductivity in radial or tangential directions (across the grain), with a smaller difference between radial and tangential directions [12,13]. When wood is considered a part of building enclosure assemblies, often such differences are overlooked by designers and manufacturers. However, the lack of consideration can result in an unintended error in estimating thermal performance for a specific energy-saving goal. That is, such differences should be reflected in the process of heat transfer calculation when designing high-performance building products such as timber windows or even timber buildings.

A few building energy simulation programs such as Design Builder and Ecotect Analysis provide thermal conductivity of wood by species as a material database for the calculation of energy usage. However, the input value differs between programs, which makes the result unreliable $[14,15]$. Heat transfer analysis programs such as THERM and HEAT2 do not provide any detailed data about the conductivity of wood by species besides a few wood-based panels. When calculating the thermal performance of a window, glass is a decisive factor for reducing heat transmittance of the product as glass has low thermal conductivity. Conversely, in general, window frames have higher thermal conductivity compared to that of glasses, meaning that material selection for window frames should be considered very carefully. For results of heat transfer analysis of timber windows to be more reliable, wood species' detailed input values should be provided to users. Changes in thermal conductivity by each anatomical direction should not be overlooked as they also affect the thermal performance of windows.

The main purpose of this paper is to build reference data of the thermal conductivity of various wood species with differences in anatomical direction for further development of high-performance timber windows and other building products. The parametric heat transfer analysis of timber windows in this research aims to reduce unintended errors when manufacturers or designers have specific goals in the hygrothermal performance of timber windows - such as heat loss reduction and condensation resistance-without any knowledge of thermal conductivity differing between wood species and anatomical direction. With an emphasis on the anistropic characteristics of wood and its impact on the hygrothermal performance of timber-based windows, the outcome of this research can be of great use for designers and engineers.

\subsection{Scope}

Figure 1 illustrates the brief outline of this research flow in three steps. The first part of the research measured the thermal conductivity of wood species with two different axes: radial and tangential direction. If the thermal conductivity characteristics are different depending on the measurement direction, such as in wood, it is necessary to accurately know the thermal conductivity in consideration of the direction and angle of the element suitable for the particular application. As a long linear element is commonly used in designing a window frame, the thermal conductivity in the radial and tangential directions, excluding the fiber direction, becomes an important factor in heat transfer. Therefore, in this 
study, the measurement results for radial and tangential directions were compared for each wood species. Since the degree angle of wood can also influence the difference regarding the main sawn direction [16], this study measured the thermal conductivity of the sawn wood in the principal direction. Following results from the previous study (Vay et al., 2015) showing approximately $8.1-17.6 \%$ of the difference in thermal conductivity between radial and tangential direction, it was anticipated there would be a certain amount of the difference that should not be overlooked.

The next part was a comparative analysis of thermal transmittance (U-value) of several timber window frames with different wood proportions in the frame design, wood species, and anatomical direction. The U-value of the frame may vary depending on factors such as the aforementioned wood species and placed orientation [17] and other parameters. For instance, changes in window spacers and glazing greatly affect the overall performance of the window [18-20]. Besides, when the application ratio of wood is changed in designing windows, the shape of other design elements of the frame is inevitable, which also makes changes in heat flow [21]. Therefore, to prevent the possibility of misinterpretation due to these unintended variables, this study focused on the sensitivity analysis of individual windows according to the change of the set variables-wood species and anatomical direction-rather than the specific performance comparison according to the type of window.

Finally, a performance assessment of timber windows with a focus on heat and moisture resistance was performed to analyze the impact of varying thermal properties in wood. Specifically, it was examined whether improvement of the U-value of window frames by wood considerations also strengthens resistance to condensation on the surface of wood or not, which is also called condensation resistance $(\mathrm{CR})$ and is extremely important for any timber-based windows because of the moisture issue. Often there are cases when the improvement of a window component such as glazing is not linearly related to CR. Even though there are significant changes in U-value by different glazing configurations, inconsistent changes in CR can be shown [22]. This is because CR is determined by the lowest surface temperature of windows. As high-performance glazing is easily achieved, it is important that the thermal performance of the frame and edge of the glass are improved, which can reduce the U-value of the overall window by $36 \%$ [23].
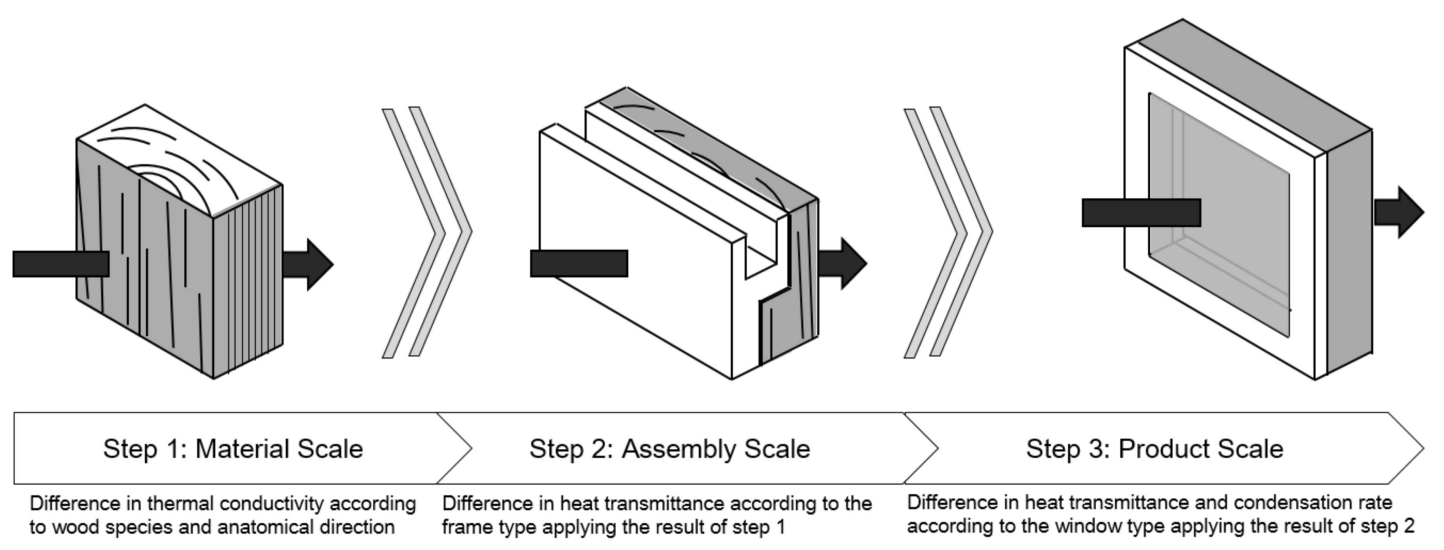

Figure 1. Research workflow: from raw material to frame assembly to product scale.

\section{Materials and Methods}

\subsection{Materials}

Five types of hardwoods, including ash, cherry, maple, white oak, and walnut, were selected for the measurement of thermal conductivity since they have been widely used for windows and other building products. Wood samples were delivered after being sourced and then cut into small pieces with a size of $12.7 \mathrm{~mm}$ in width and height, which was recommended from a manual for the measuring instrument. For the reliability of the measurement, sample surfaces were prepared to be flat 
and smooth with the thickness ranging from $1 \mathrm{~mm}$ to $2 \mathrm{~mm}$, which was also specified in the manual. Samples were cut to have two different sections—radial and tangential—for measurement of the main directional heat flow (Figure 2). A minimum of three samples was measured for each wood species and anatomical direction.

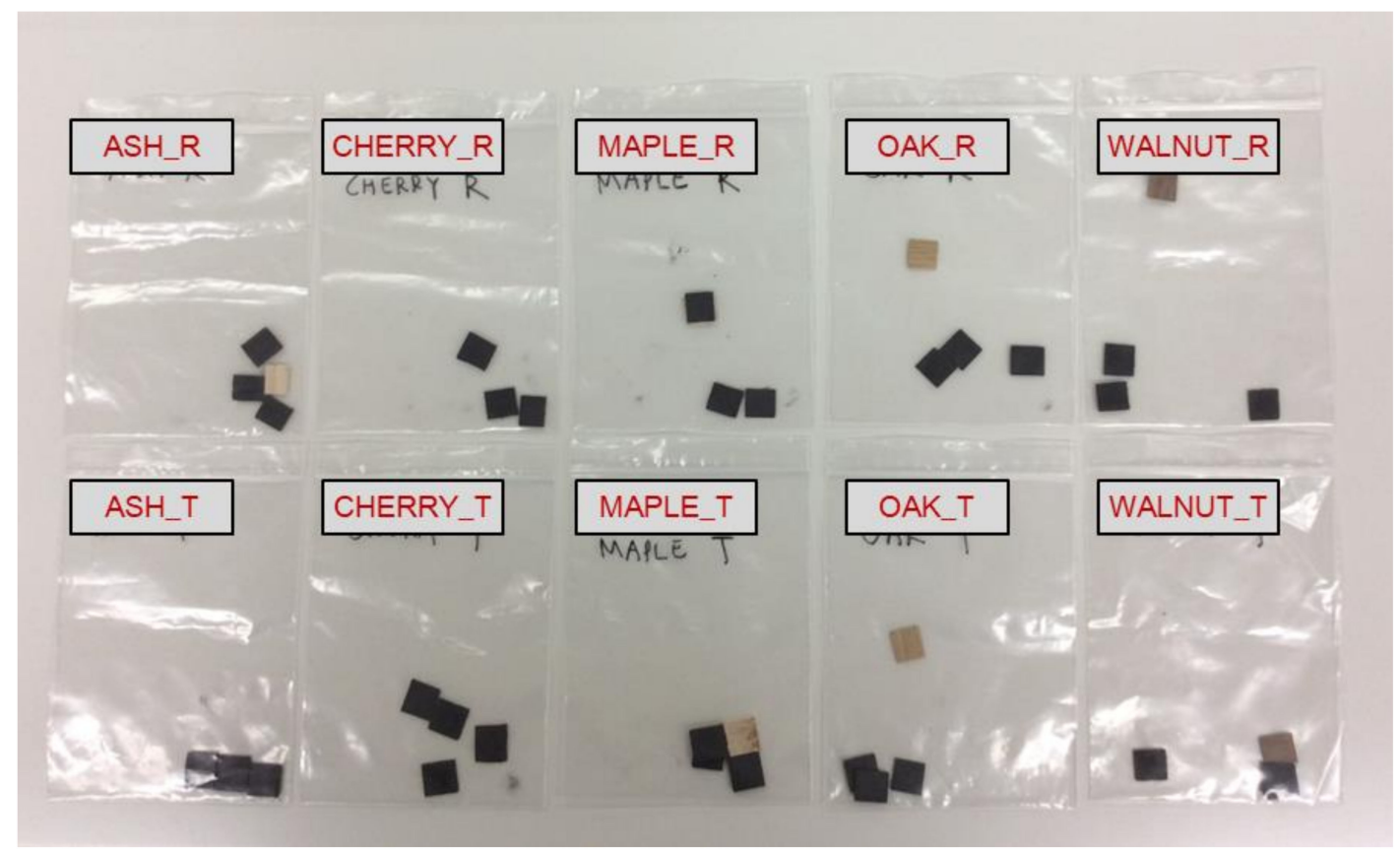

Figure 2. Sample preparation of five types of hardwoods.

\subsection{Methods}

\subsubsection{Measurement of Thermal Conductivity}

There are three main measurement techniques for the thermal conductivity of building materials, which are the steady-state method using guarded hot plate, transient hot-wire method, and laser flash method using laser flash apparatus [24,25]. The advantage of the laser flash method is that it reduces the measurement time, and it allows relatively small samples with a wide range of materials compared to other methods [26]. Among the three analytical methods, the laser flash method was applied using an apparatus from Netzsch (Figure 3).

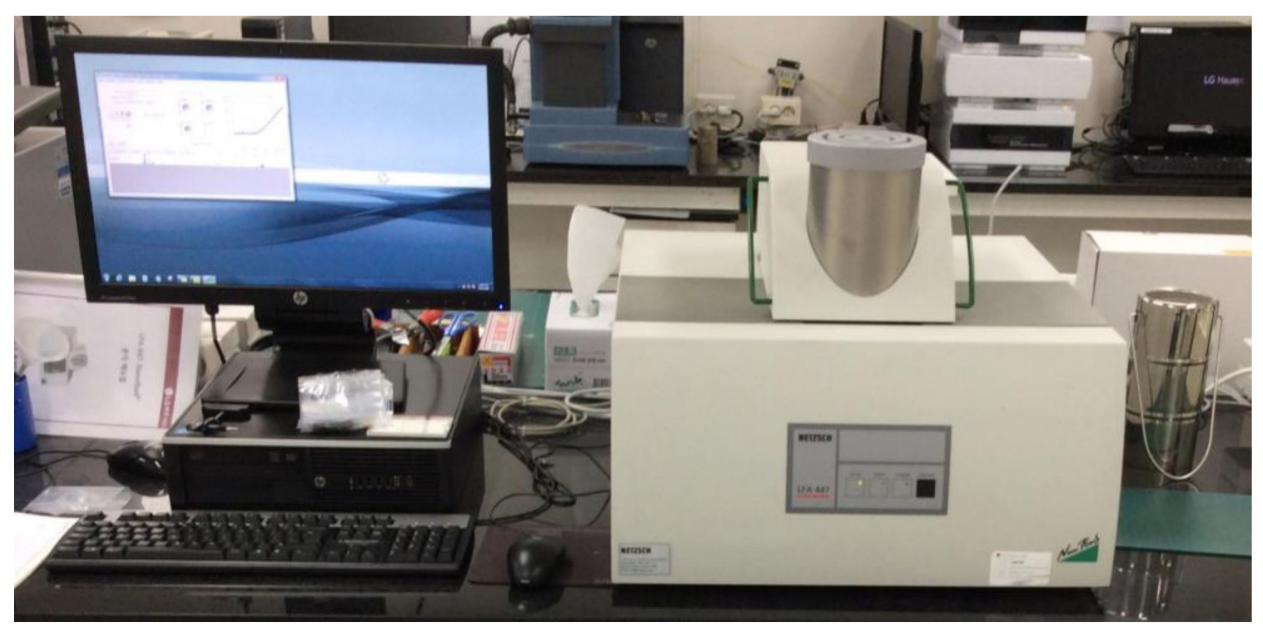

Figure 3. Apparatus used for the measurement (LFA-447). 
To calculate the thermal conductivity of materials using LFA, thermal diffusivity should be measured at first. To measure thermal diffusivity, the lower surface is heated by a laser pulse, and then temperature change on the opposite surface is detected. Using the half measurement time and sample thickness, the thermal diffusivity, and finally, the thermal conductivity can be calculated using Equations (1) and (2).

$$
\begin{gathered}
a=0.1388 \cdot d^{2} / \mathrm{t}_{1 / 2} \\
\lambda=a \cdot c_{p} \cdot \rho
\end{gathered}
$$

where $a$ is the thermal diffusivity $\left(\mathrm{mm}^{2} / \mathrm{s}\right), d$ is the sample thickness $(\mathrm{mm}), c_{p}$ is the specific heat capacity $(\mathrm{J} / \mathrm{kg} \cdot \mathrm{K}), \rho$ is the density $\left(\mathrm{kg} / \mathrm{m}^{3}\right)$, and $\lambda$ is the thermal conductivity $(\mathrm{W} / \mathrm{m} \cdot \mathrm{K})$. Ten iterative measurement values have been averaged for each sample.

\subsubsection{Calculation of Heat Transmittance of Window Frames}

For comparative analysis of heat transfer through window frames with different wood compositions, three types of the commercially available timber-based window have been referenced; traditional timber window, aluminum-clad timber window, and timber-clad aluminum window are modeled for the analysis (Table 1).

Table 1. Types of timber-based windows for the analysis.

\begin{tabular}{cccc}
\hline Window Type & Opening Type & Glazing Type & Graphical Representation \\
Timber Window & Horizontal Slider & $22 \mathrm{~mm}$ Double Pane \\
$(5 \mathrm{cl}+12$ argon+5 lowE $)$ \\
Aluminum-Clad Timber
\end{tabular}

When it is necessary to measure the U-value of various types of windows with different wood species and directions, it is very costly and time consuming to prepare mock-ups for measurement. In consideration of practical problems, the U-value was calculated using THERM, a simulation program used to evaluate the performance of windows instead of actual measurement. The program, which was developed by LBNL (Lawrence Berkeley National Laboratory), is a two-dimensional heat transfer analysis program that is the most popular in the world when designing windows. It is widely used as the program is provided for free and is used for certification of passive house products [27]. 
To proceed with the analysis, a user should either import the CAD drawing of window frames or draw the shape directly. Besides, to calculate the heat transmittance of various windows, the property values of the materials should be specified. In this study, a drawing was prepared by referring to the customer product brochures and exhibits published outside. For the thermal conductivity of materials other than wood, the general value provided by the program was applied. The thermal conductivity of wood reflected the measured value obtained through the measurement. The timber frames for comparison were set to a quarter sawn and flat sawn (Figure 4), as it is realistic for frame materials to be sourced along the longitudinal direction.
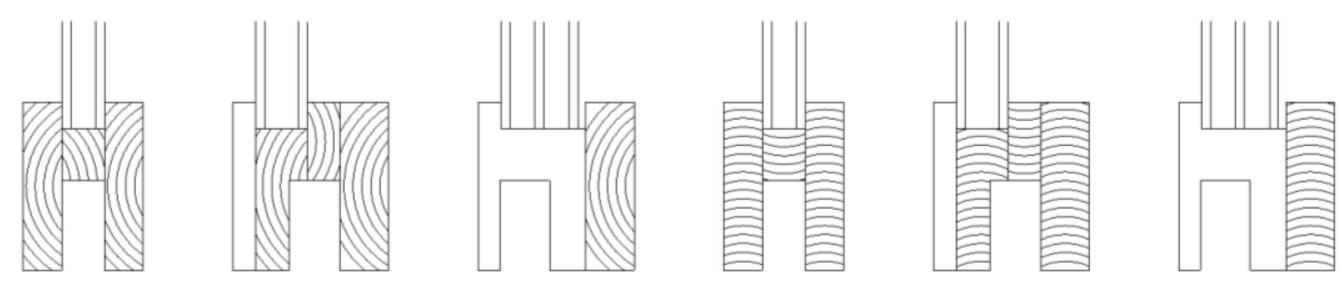

Figure 4. Conceptual drawing of window frames with a different sawn direction.

\subsubsection{Calculation of Heat Transmittance (U-value) and Condensation Resistance (CR) of Windows}

The U-value and CR of windows based on precalculated U-values of window frames were estimated for comparison of overall thermal performance with a focus on the effect of the selection of wood species and fiber directions. WINDOW, a program also developed by LBNL, was used to calculate the performance of windows with U-value and CR of window frames data coupling from THERM. Condensation resistance is an index expressed as a value between 1 and 100 by comparing the condensation prevention performance of the interior of windows and doors under environmental conditions specified in NFRC 500-2020 [28], an association standard provided by the National Federation Rating Council (NFRC) of the United States. In the case of all timber and timber hybrid windows, as wood is exposed on the interior surface, the CR based on the interior surface to be calculated in this study would have an important influence on the design of the window, considering the characteristics of wood related to the moisture. Overall, impacts of changes in wood species and anatomical direction have been examined from two perspectives: one as the thermal performance related to the $\mathrm{U}$-value, and the other as the durability issue from the condensation risk.

\section{Results and Discussion}

\subsection{Thermal Conductivity of Wood}

For the calculation of thermal diffusivity, and finally the thermal conductivity, the density of each wood species was measured using the electronic densimeter with precision $0.0001 \mathrm{~g}$. Specific heat values were calculated following Volbehr's previous work completed in 1896 [29]. Equation (3) is described below:

$$
c_{p}=0.2590+0.000975 m+0.000605 T+0.000025 m T
$$

where $c_{p}$ is the specific heat capacity $(\mathrm{cal} / \mathrm{g} \cdot \mathrm{C}), m$ is the moisture content between 0 and $27 \%$, and $T$ is the endpoint temperature over the range of $0{ }^{\circ} \mathrm{C}$ to $100{ }^{\circ} \mathrm{C}$. The moisture content of wood species was measured before sample preparation following ISO 13061-1 [30], and then samples were stored in the laboratory with a constant temperature of $25( \pm 1)^{\circ} \mathrm{C}$ and $50( \pm 5) \%$ relative humidity before the measurements. For the measurement of thermal diffusivity, the temperature in the chamber was set to $25^{\circ} \mathrm{C}$, which is close to normal room temperature. Table 2 lists the results of the thermal diffusivity and conductivity measurements of each wood species. Detailed measurement data are also provided in Table S1. 
Table 2. Thermal diffusivity and conductivity of wood species in radial and tangential directions.

\begin{tabular}{|c|c|c|c|c|c|c|c|}
\hline \multirow{2}{*}{$\begin{array}{l}\text { Wood } \\
\text { Species }\end{array}$} & \multirow{2}{*}{$\begin{array}{l}\text { Moisture } \\
\text { Content } \\
(\%)\end{array}$} & \multirow[t]{2}{*}{$\operatorname{Density}\left(\mathrm{kg} / \mathrm{m}^{3}\right)$} & \multirow{2}{*}{$\begin{array}{l}\text { Specific Heat } \\
(\text { cal } / \mathrm{g} \cdot \mathrm{C})^{1}\end{array}$} & \multicolumn{2}{|c|}{$\begin{array}{l}\text { Thermal Diffusivity } \\
\left(\mathrm{mm}^{2} / \mathrm{s}\right)\end{array}$} & \multicolumn{2}{|c|}{$\begin{array}{l}\text { Thermal Conductivity } \\
(\mathrm{W} / \mathrm{m} \cdot \mathrm{K})\end{array}$} \\
\hline & & & & Radial & Tangential & Radial & Tangential \\
\hline Ash & 13.3 & 670 & 0.292 & $\begin{array}{c}0.179 \\
( \pm 0.002)\end{array}$ & $\begin{array}{c}0.154 \\
( \pm 0.010)\end{array}$ & $\begin{array}{c}0.147 \\
( \pm 0.002)\end{array}$ & $\begin{array}{c}0.127 \\
( \pm 0.008)\end{array}$ \\
\hline Cherry & 12.4 & 697 & 0.291 & $\begin{array}{c}0.221 \\
( \pm 0.010)\end{array}$ & $\begin{array}{c}0.157 \\
( \pm 0.002)\end{array}$ & $\begin{array}{c}0.181 \\
( \pm 0.008)\end{array}$ & $\begin{array}{c}0.129 \\
( \pm 0.001)\end{array}$ \\
\hline Maple & 13.2 & 732 & 0.292 & $\begin{array}{c}0.190 \\
( \pm 0.006)\end{array}$ & $\begin{array}{c}0.149 \\
( \pm 0.003)\end{array}$ & $\begin{array}{c}0.156 \\
( \pm 0.005)\end{array}$ & $\begin{array}{c}0.122 \\
( \pm 0.002)\end{array}$ \\
\hline $\begin{array}{l}\text { Oak, } \\
\text { White }\end{array}$ & 13.8 & 884 & 0.293 & $\begin{array}{c}0.206 \\
( \pm 0.010)\end{array}$ & $\begin{array}{c}0.165 \\
( \pm 0.001)\end{array}$ & $\begin{array}{c}0.169 \\
( \pm 0.008)\end{array}$ & $\begin{array}{c}0.136 \\
( \pm 0.001)\end{array}$ \\
\hline Walnut & 11.3 & 566 & 0.289 & $\begin{array}{c}0.185 \\
( \pm 0.002)\end{array}$ & $\begin{array}{c}0.162 \\
( \pm 0.002)\end{array}$ & $\begin{array}{c}0.152 \\
( \pm 0.002)\end{array}$ & $\begin{array}{c}0.133 \\
( \pm 0.001)\end{array}$ \\
\hline
\end{tabular}

${ }^{1}$ For the calculation of thermal conductivity, $1 \mathrm{cal} / \mathrm{g} \cdot \mathrm{C}$ has been converted to $4200 \mathrm{~J} / \mathrm{kg} \cdot \mathrm{K}$.

As a result of a series of measurements performed, the heat transfer rate of all wood species was found lower in tangential direction compared to that of radial direction; the thermal conductivity of selected wood species ranged from $0.12 \mathrm{~W} / \mathrm{m} \cdot \mathrm{K}$ to $0.14 \mathrm{~W} / \mathrm{m} \cdot \mathrm{K}$ for tangential direction and from $0.15 \mathrm{~W} / \mathrm{m} \cdot \mathrm{K}$ to $0.18 \mathrm{~W} / \mathrm{m} \cdot \mathrm{K}$ for radial direction. Overall, all the measured values fell within the range of $0.12-0.18 \mathrm{~W} / \mathrm{m} \cdot \mathrm{K}$, which aligns with previous studies of $0.10-0.21 \mathrm{~W} / \mathrm{m} \cdot \mathrm{K}$ (TenWolde and McNatt and Krahn, 1988) and 0.14-0.19 w/m·K (Jankowska and Kazakiewicz, 2014). Inconsistency between wood density and thermal conductivity was exhibited, which was also shown in the previous study (Aggrey-Smith and Preko and Owusu, 2016), as thermal conductivity also depends on various factors other than the density of the wood.

For each wood species, the difference in avergated thermal conductivity between radial and tangential directions varied (Figure 5).

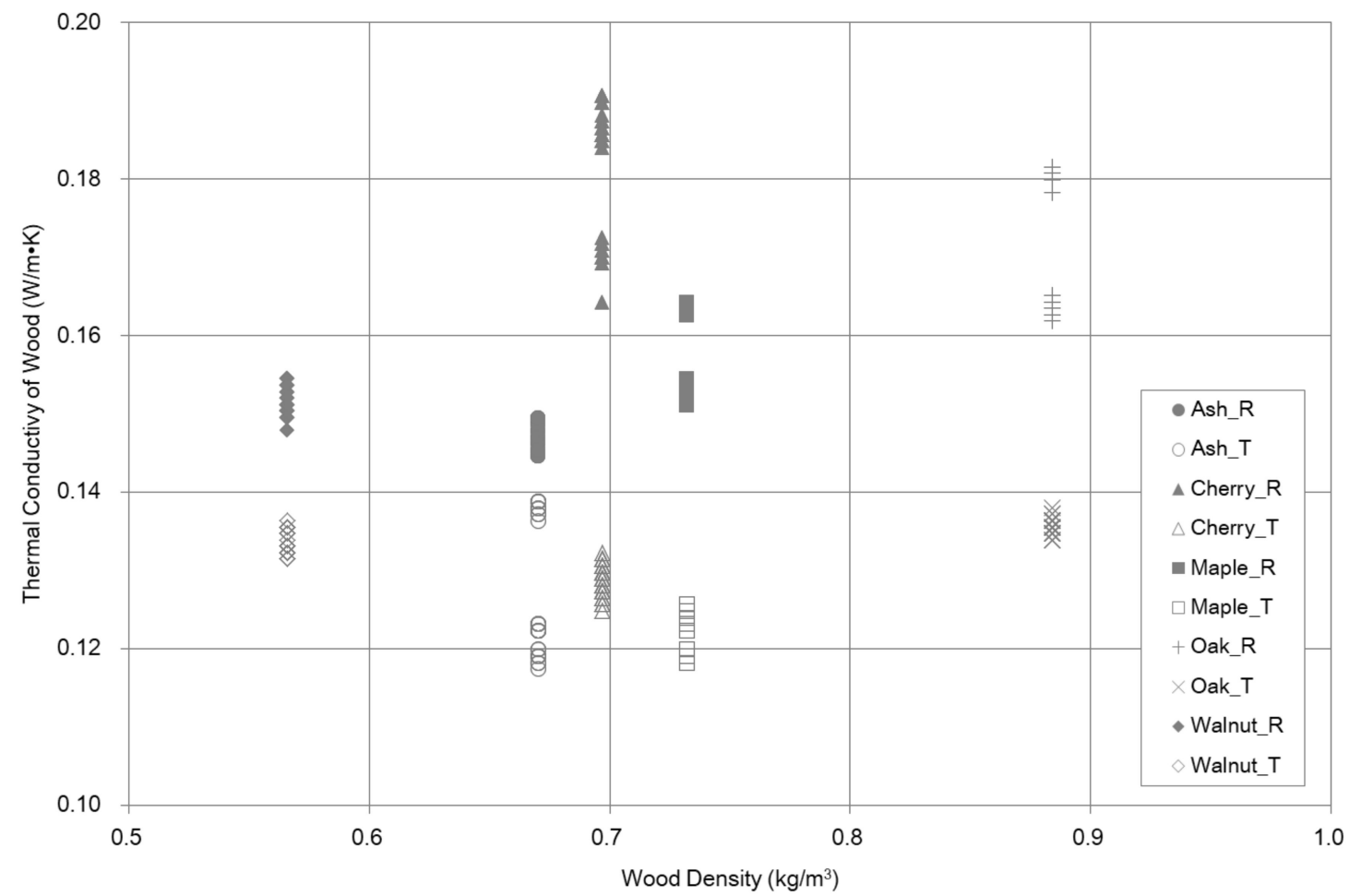

Figure 5. Thermal conductivity of wood species in radial and tangential directions. 
The thermal conductivity of oak in the radial direction was about $24.3 \%$ higher than that of the tangential direction, whereas $17.1 \%$ of the difference was found in the previous study (Vay et al., 2015). However, regarding the standard deviation shown in the two studies, the difference fell within the acceptable rate. There was the least value of the proportional difference in walnut, which was approximately $12.5 \%$ on average, whereas the measurement result of cherry showed approximately $28.7 \%$ difference on average when the direction changed from radial to tangential. The results show that the selection of species and sawn direction of wood for designing building components would affect the thermal performance of products.

\subsection{Heat Transmittance of Window Frames}

To acquire the U-value of window frames, the simplified drawing of each window frame was created in THERM for the calculation. For the boundary condition of the exterior and interior surfaces, the temperature was set to $-18{ }^{\circ} \mathrm{C}$ and $21^{\circ} \mathrm{C}$, respectively, which is a default setting in the program and also specified in NFRC 100-2020 [31]. The thermal properties of materials except wood are summarized in Table 3, and are referenced from NFRC 100-2020 and ISO 10077-2 [32].

Table 3. Thermal properties of materials used in THERM.

\begin{tabular}{ccc}
\hline Material & Thermal Conductivity $\mathbf{( W / m \cdot K )}$ & Reference \\
\hline Aluminum & 160 & ISO 10077-2 \\
EPDM (gasket) & 0.25 & ISO 10077-2 \\
Frame cavity & automatically calculated for & ISO 10077-2 \\
Frame cavity & each cavity within THERM & \\
(slightly ventilated) & & ISO 10077-2 \\
Mohair & 0.14 & NFRC 100 \\
Spacer & 0.01 & ISO 10077-2 \\
Steel & 50 & - \\
Wood & measured value & NFRC \\
Urethane & 0.12 & \\
(thermal break) & &
\end{tabular}

The results from the series of calculations are listed in Table 4. Graphical representations with detailed results in THERM are also provided (Table S2).

Table 4. Summary of window type categories for the analysis with resulting U-value.

\begin{tabular}{|c|c|c|c|c|}
\hline Window Type & Wood Species & $\begin{array}{c}\text { Anatomical } \\
\text { Direction }\end{array}$ & ID & $\begin{array}{c}\text { U-value of } \\
\text { Window Frame } \\
\left(\mathrm{W} / \mathrm{m}^{2} \cdot \mathrm{K}\right)\end{array}$ \\
\hline \multirow{10}{*}{ Timber Window } & \multirow{2}{*}{ Ash } & Radial & T-AR & 1.908 \\
\hline & & Tangential & T-AT & 1.764 \\
\hline & \multirow{2}{*}{ Cherry } & Radial & $\mathrm{T}-\mathrm{CR}$ & 2.124 \\
\hline & & Tangential & $\mathrm{T}-\mathrm{CT}$ & 1.779 \\
\hline & \multirow{2}{*}{ Maple } & Radial & T-MR & 1.969 \\
\hline & & Tangential & T-MT & 1.725 \\
\hline & \multirow{2}{*}{ Oak, White } & Radial & T-OR & 2.052 \\
\hline & & Tangential & T-OT & 1.831 \\
\hline & \multirow{2}{*}{ Walnut } & Radial & T-WR & 1.942 \\
\hline & & Tangential & T-WT & 1.809 \\
\hline
\end{tabular}


Table 4. Cont.

\begin{tabular}{|c|c|c|c|c|}
\hline Window Type & Wood Species & $\begin{array}{l}\text { Anatomical } \\
\text { Direction }\end{array}$ & ID & $\begin{array}{c}\text { U-value of } \\
\text { Window Frame } \\
\left(\mathrm{W} / \mathrm{m}^{2} \cdot \mathrm{K}\right)\end{array}$ \\
\hline \multirow{10}{*}{$\begin{array}{l}\text { Aluminum-Clad } \\
\text { Timber Window }\end{array}$} & \multirow{2}{*}{ Ash } & Radial & AcT-AR & 2.422 \\
\hline & & Tangential & AcT-AT & 2.316 \\
\hline & \multirow{2}{*}{ Cherry } & Radial & AcT-CR & 2.566 \\
\hline & & Tangential & AcT-CT & 2.327 \\
\hline & \multirow{2}{*}{ Maple } & Radial & AcT-MR & 2.465 \\
\hline & & Tangential & AcT-MT & 2.287 \\
\hline & \multirow{2}{*}{ Oak, White } & Radial & AcT-OR & 2.516 \\
\hline & & Tangential & AcT-OT & 2.365 \\
\hline & \multirow{2}{*}{ Walnut } & Radial & AcT-WR & 2.446 \\
\hline & & Tangential & AcT-WT & 2.409 \\
\hline \multirow{10}{*}{$\begin{array}{l}\text { Timber-Clad } \\
\text { Aluminum } \\
\text { Window }\end{array}$} & \multirow{2}{*}{ Ash } & Radial & TcA-AR & 2.219 \\
\hline & & Tangential & TcA-AT & 2.146 \\
\hline & \multirow{2}{*}{ Cherry } & Radial & TcA-CR & 2.317 \\
\hline & & Tangential & TcA-CT & 2.154 \\
\hline & \multirow{2}{*}{ Maple } & Radial & TcA-MR & 2.248 \\
\hline & & Tangential & TcA-MT & 2.126 \\
\hline & \multirow{2}{*}{ Oak, White } & Radial & TcA-OR & 2.285 \\
\hline & & Tangential & TcA-OT & 2.181 \\
\hline & \multirow{2}{*}{ Walnut } & Radial & TcA-WR & 2.235 \\
\hline & & Tangential & TcA-WT & 2.170 \\
\hline
\end{tabular}

It should be noticed that although the geometric characteristics of wood are the same, up to $11.3 \%$ of the difference in the U-value of the window frame could be found depending on the wood selection. The U-value could increase up to $19.4 \%$ if the sawn direction of wood components in the window frame changes from radial to tangential while the type of wood remains the same. Those results align with a finding from the previous study that changes in the frame and edge without changing the glazing system could even greatly reduce the U-value of the window. This indicates the wood design in window frames could also be a critical issue.

It should be stated that depending on the type of windows, the impact of changes in the thermal conductivity of wood varies. Figure 6 illustrates the range of the U-value of the frame by window types according to the selection of wood and its anatomical direction.

It was found that the range of changes in the U-value was reduced as the proportion of wood was decreased. Up to $23 \%$ of the difference was calculated with an assumption of the window frames being solely made of wood, whereas cases of the timber-clad aluminum window frame resulted in a $9 \%$ difference. While aluminum-clad timber window frames showed up to $12 \%$ difference, the average $\mathrm{U}$-value of frames was the highest among three window types since the frame lacked a thermal break. The results showed that timber-clad aluminum window frames have relatively low value compared to that of aluminum-clad timber window frames since thermal breaks are applied within the frames of timber-clad aluminum windows. According to the analysis, timber window frames had relatively lower U-value as wood has relatively lower thermal conductivity compared to that of aluminum. 


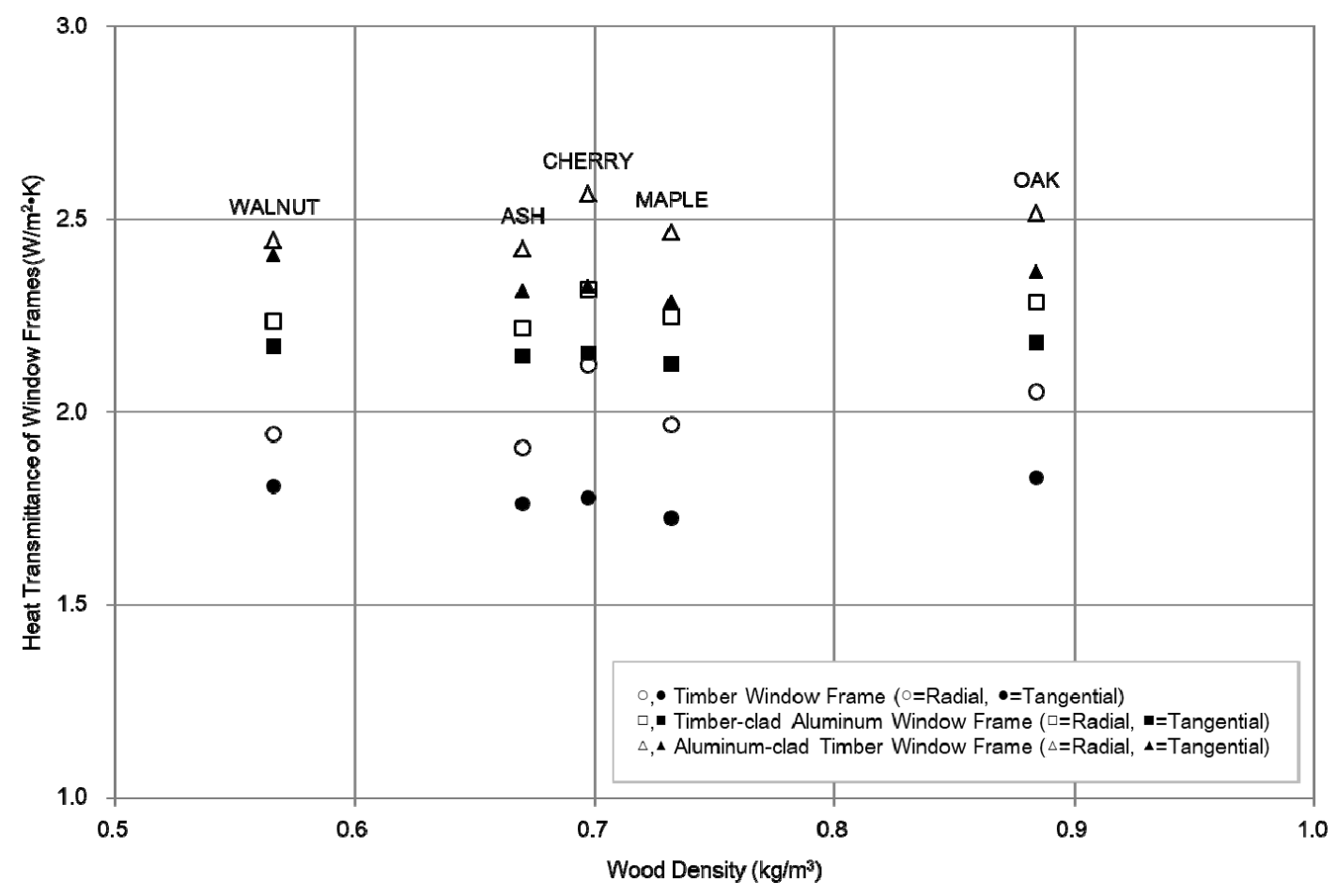

Figure 6. U-value of window frames with different wood species and anatomical direction.

\subsection{Heat Transmittance and Condensation Resistance of Windows}

Window frames modeled in THERM were imported to WINDOW to calculate the U-value and the $\mathrm{CR}$ of overall window products by specifying the glazing system and opening type of the window. The program calculated the U-value using Equation (4).

$$
U_{w}=\left(\sum U_{g} \cdot A_{g}+\sum U_{f} \cdot A_{f}+\sum \psi_{g} \cdot l_{g}\right) /\left(\sum \mathrm{A}_{g}+\sum A_{f}\right)
$$

where $U_{x}$ is the heat transmittance of each window component $(\mathrm{x}=\mathrm{w}$-overall window product, $\mathrm{f}$-window frame, g-center of glass), $\psi_{g}$ is the linear heat transmittance of glass edge, $A x$ is the area of each window component ( $x=$ g-glass, $f$-frame), $l_{g}$ is the length of the glass edge.

The program also calculated the condensation rate using Equation (5) [33].

$$
C R_{x}=\left[1-\left[\sum \mathrm{j}=1,2,3\left\{\sum\left(T_{d p, j}-T_{i}\right)^{+} \cdot A_{x, i}\right\} /\left\{\left(T_{d p, j}-T_{0}\right) \cdot A_{x}\right\}_{\mathrm{j}}=\mathrm{RH} @ 30,50,70 \%\right]^{1 / 3} / 3\right] \cdot 100
$$

where $C R_{x}$ is the condensation resistance of each window component $(\mathrm{x}=\mathrm{w}$-overall window product, e-edge of glass, f-window frame, g-center of glass), $T_{d p, j}$ is the dew point temperature, $T_{i}$ is the indoor temperature, $T_{o}$ is the outdoor temperature, $A_{x}$ is the area of each window component (e-edge of glass, $\mathrm{f}$-window frame, g-center of glass) in the interior surface.

With environmental conditions following NFRC 100-2020, the results from the series of calculations are summarized in Figure 7. WINDOW calculation data of each component and the overall product are provided in detail (Table S3).

For each window type, as the glazing system remains the same, changes in the U-value of the edge of the glass are negligible regardless of various wood species and their anatomical direction. As glass is an important factor in determining the thermal performance of the window, the overall U-value of window products would be lowered as the glazing system with high performance is applied. However, varying U-value of window frames as calculated in the previous analysis could also affect the U-value of overall window products, as the results have shown - the number of changes differed by window types. For timber windows being analyzed in this research, approximately $10.3 \%$ of ranging U-value 
was calculated if a specific type of wood and sawn direction are chosen. In cases of aluminum-clad timber windows, up to $7.9 \%$ of the difference was calculated when compared from the highest to the lowest. A relatively low range of $6.1 \%$ among cases for timber-clad aluminum windows was estimated since the proportion of wood elements in the frame design was assumed.

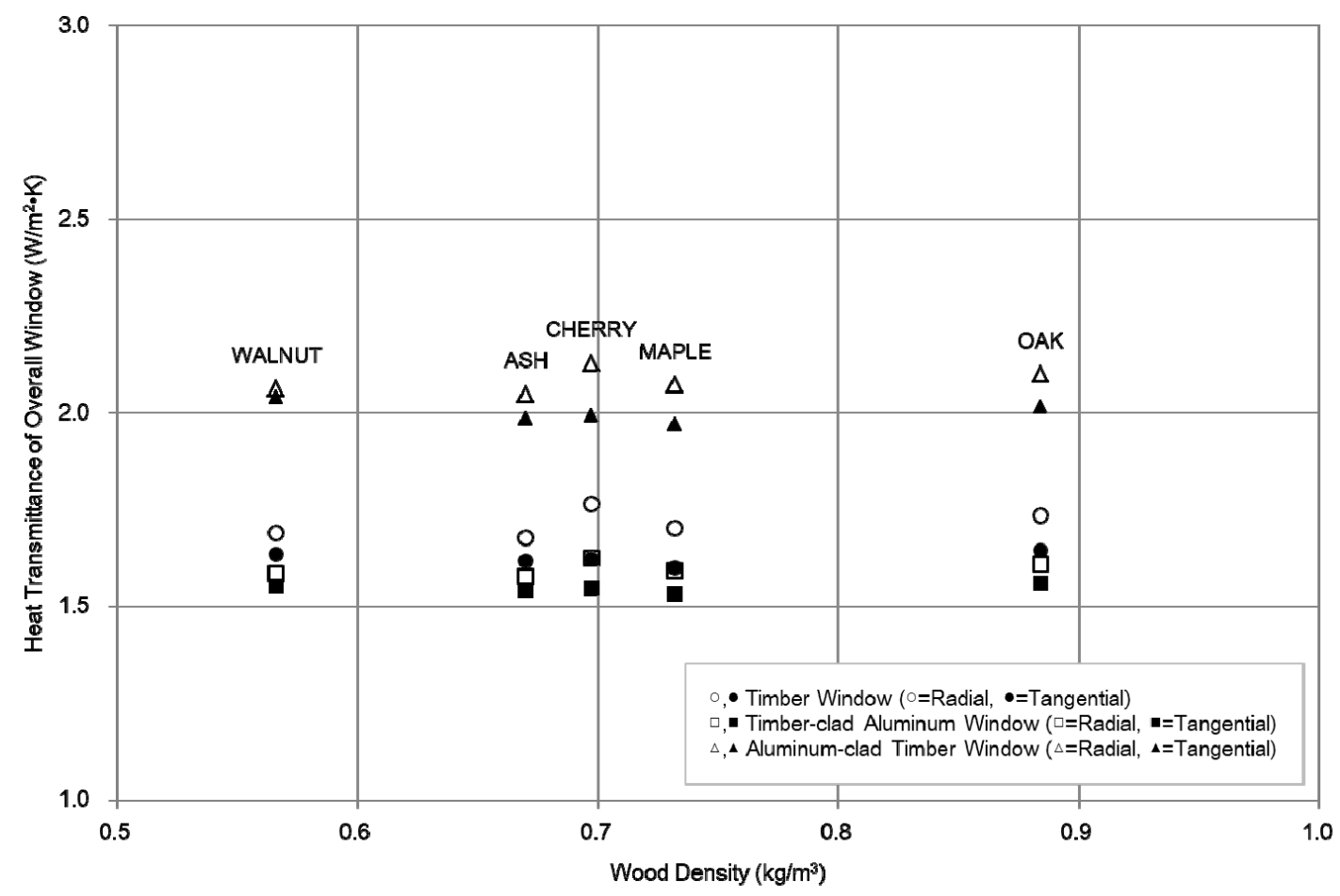

Figure 7. U-value of window components and overall window products compared.

The CR of each window component for three relative humidity levels was considered for the calculation specified in NFRC 500-2020. For the individual cases, the minimum CR among the results from a window frame, an edge, and a center of glass was regarded as the final value. As indicated in Figure 8, the CR of each window frame fluctuated as material properties of the wood element in the window frame changed, whereas that of the edge of each glass remained stable. The CR of the edge of the glass can be lower than that of window frames when frames are made of materials with low thermal conductivity, and the thermal performance of the glazing system is not sufficiently high. For all cases, the CR of the center of glass was the highest as it is common that glass on contemporary windows has relatively high performance.

As previous studies have implemented, the overall CR did not always have a linear correlation with the U-value as the thermal performance of a window was improved (Figure 9). Through the series of heat transfer analysis of windows, it was found that the U-value and the CR have a linear relationship for cases except for timber windows. As the thermal performance was improved by changing either wood species or anatomical direction, achieving lower thermal conductivity, condensation resistance was improved as well. For timber windows, however, an only marginal improvement on the condensation resistance was found, although U-value was lowered. The reason was that the glazing system had not been changed throughout the analysis, and the minimum value among calculations from window parts was set to overall CR. As per results, for higher overall CR, both the edge of the glass and window frames should be thermally improved depending on a specific window type. 


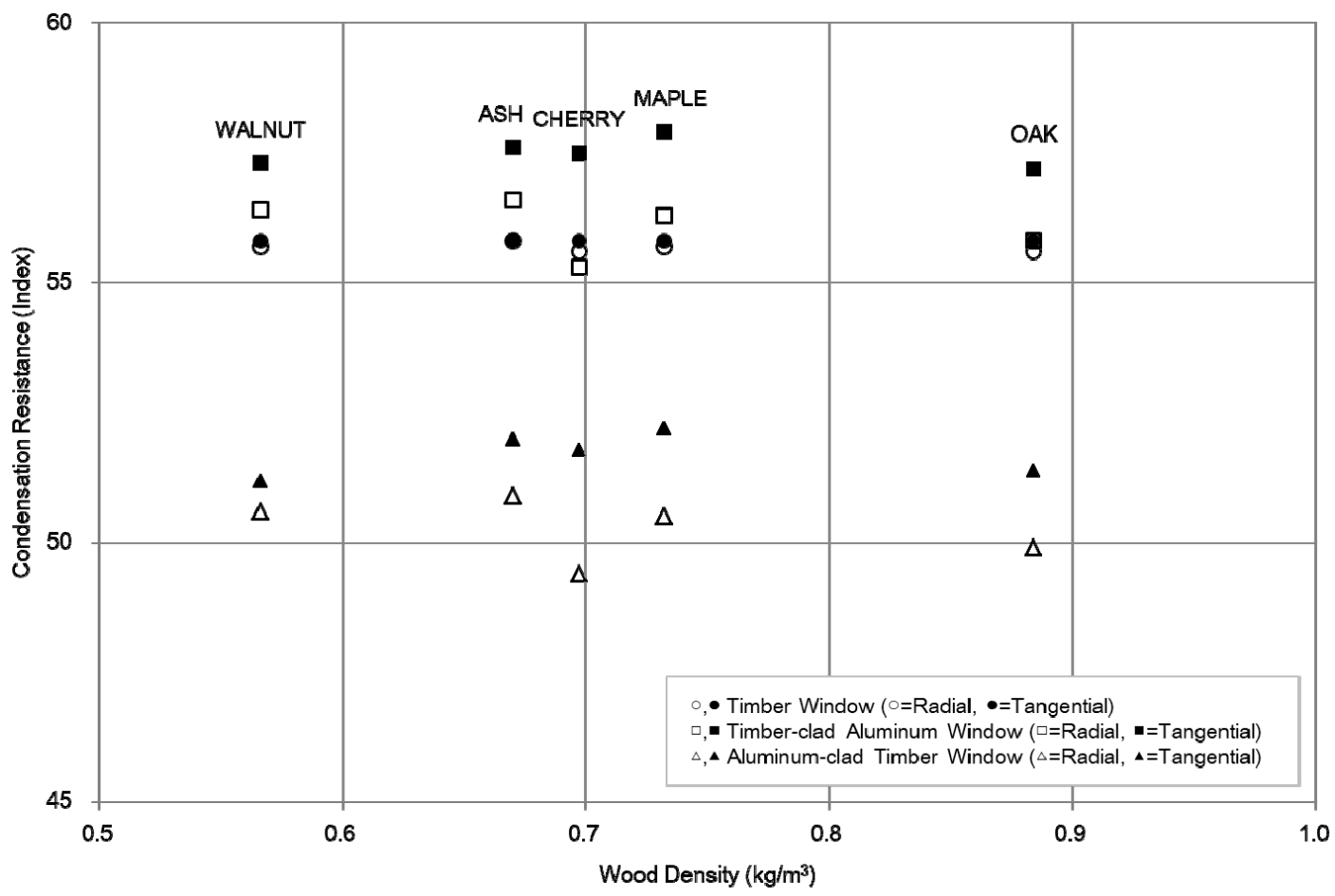

Figure 8. CR of window components and overall window products compared.

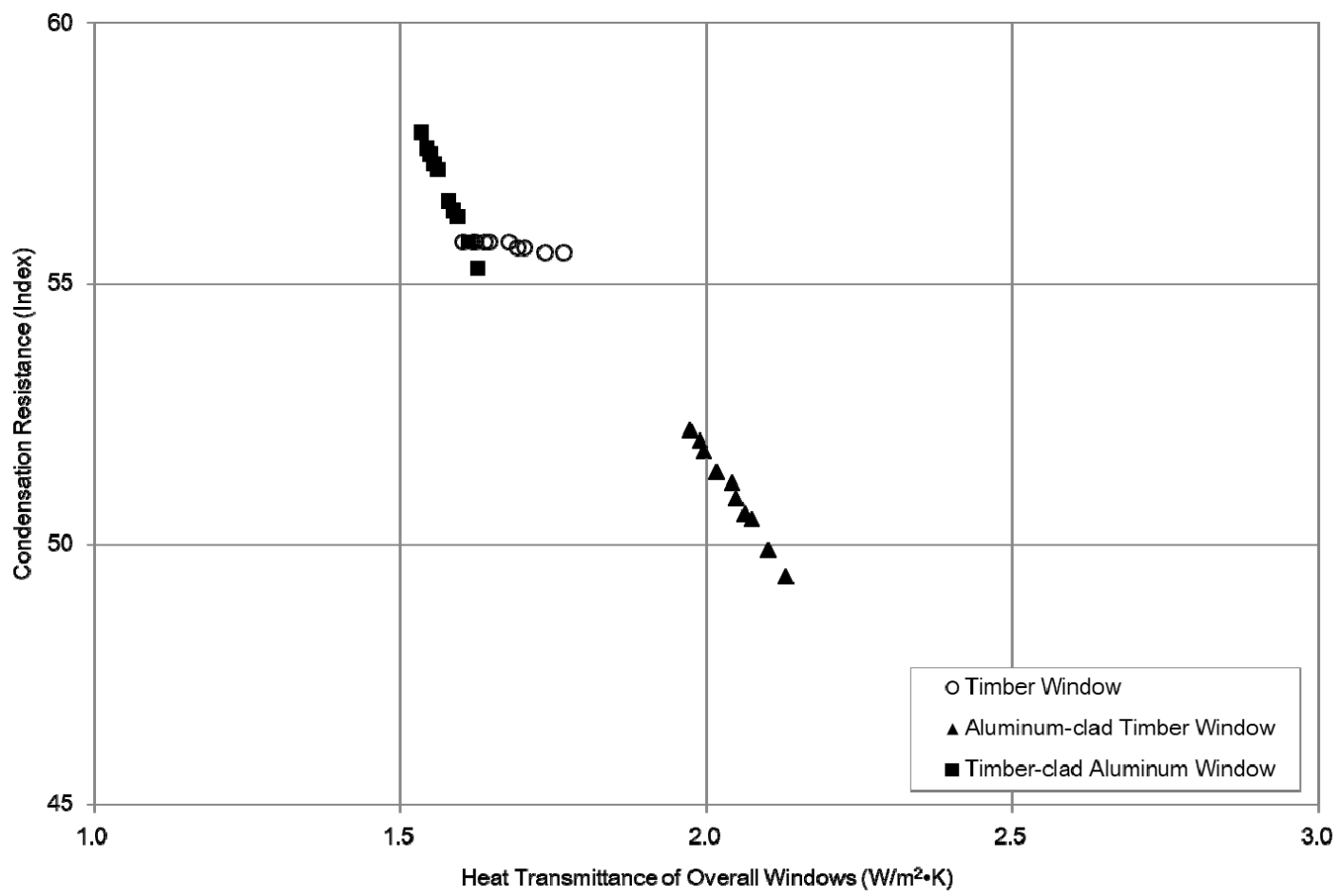

Figure 9. Correlation analysis for heat transmittance and condensation resistance of timber windows with changes in wood species and anatomical direction.

As results indicated, the selection of wood in detail is important in improving both U-value and CR in general. Selecting a high-performance glazing system could also be considered to avoid additional condensation risk on the edge of the glass. 


\section{Conclusions}

The main objective of this study was to identify the impact of differences in thermal conductivity of various wood species and anatomical directions on the hygrothermal performance of timber-based windows. To evaluate the performance of windows, measurements of thermal conductivity were performed using LFA. Then, each window frame was modeled in a heat transfer analysis program to calculate thermal conductivity, heat transmittance, and condensation resistance index for the comparison and the evaluation.

As a result of evaluating the heat transmittance of three different window frames with changes in wood species and anatomical direction, up to $19.4 \%$ of difference depending on the sawn direction of wood elements within the window frame design was found, whereas $11.3 \%$ of the difference was made solely by the selection of wood species. For overall window products, maximum changing rates ranged from $6.1 \%$ to $10.3 \%$ for each window type. The condensation resistance of windows was also affected by changes in the thermal properties of window frames.

When correlation analysis was performed to clarify whether changes in thermal properties of timber-based window frames by wood specification affect both the heat transmittance and condensation resistance of overall window products or not, windows, in general, showed a linear relationship if the glazing system had much higher performance than window frames. It was also found that there were cases where the thermal improvement of window frames could not lead to changes in improving overall condensation resistance unless the glazing system would improve as well. This aligns with the result from the literature that the relationship between the $U$-value and CR is neither direct nor linear, as there might still exist a localized thermal bridge across the window. The study showed that wood species and anatomical direction could improve the hygrothermal performance and durability of timber and hybrid timber windows, as decisions would affect both the amount of heat transfer and the condensation risk of the designated window frame design. It should also be stated that, however, there are always trade-offs in selecting wood species and anatomical direction. For instance, choosing a quarter-sawn wood for the frame material would result in a lower U-value, which increases the cost compared to that of the frame with flat-sawn wood. Efforts for improving the hygrothermal performance of windows by optimization of the frame and other components as well as proper environmental control would be able to minimize such trade-offs.

Supplementary Materials: The following are available online at http://www.mdpi.com/1996-1073/13/22/6050/s1, Table S1: Detailed LFA measurement values; Table S2: Results of THERM calculation for each window frame; Table S3: Results of WINDOW calculation for each window frame.

Author Contributions: Conceptualization, N.A.; methodology, N.A.; software, N.A.; validation, N.A. and S.P.; formal analysis, N.A.; investigation, N.A.; resources, N.A.; data curation, N.A.; writing-original draft preparation, N.A.; writing - review and editing, S.P.; visualization, N.A.; supervision, S.P.; project administration, N.A. and S.P. All authors have read and agreed to the published version of the manuscript.

Funding: This paper did not receive external funding.

Conflicts of Interest: The authors declare no conflict of interest.

\section{References}

1. Window and Door Market Trends \& Opportunities. In Proceedings of the Window Door Manufacturers Association 2018 Technical \& Manufacturing Conference, Minneapolis, MN, USA, 19-21 June 2018. Available online: https://www.homeinnovation.com/-/media/Files/Market_Research/WDMA-TechnicalManufacturing-PPT-Home-Innovation.pdf (accessed on 19 October 2020).

2. Jeld-Wen 2018 Annual Report. Available online: https://investors.jeld-wen.com/financials/annual-reports/ default.aspx (accessed on 19 October 2020).

3. WWF-UK. Window of Opportunity. Available online: https://www.wwf.org.uk/sites/default/files/2017-06/ windows_0305.pdf (accessed on 19 October 2020).

4. Asif, M.; Muneer, T.; Kubie, J. Sustainability Analysis of Window Frames. Build. Serv. Eng. Res. Technol. 2005, 26, 71-87. [CrossRef] 
5. Glass, S.V.; Zelinka, S.L. Moisture Relations and Physical Properties of Wood. In Wood Handbook: Wood As an Engineering Material: Chapter 4, Centennial ed.; General Technical Report FPL; GTR-190; U.S. Department of Agriculture, Forest Service, Forest Products Laboratory: Madison, WI, USA, 2010; Volume 190, pp. 4.1-4.19.

6. Kim, H. Numerical Analysis on Temperature and Moisture Profiles of Wood Considering Crack Occurrence during High Temperature Drying. Master's Thesis, Seoul National University, Seoul, Korea, 2019.

7. Yapici, F.; Ozcifci, A.; Esen, R.; Kurt, S. The Effect of Grain Angle and Species on Thermal Conductivity of Some Selected Wood Species. BioResources 2011, 6, 2757-2762.

8. Asdrubali, F.; Ferracuti, B.; Lombardi, L.; Guattari, C.; Evangelisti, L.; Grazieschi, G. A Review of Structural, Thermo-Physical, Acoustical, and Environmental Properties of Wooden Materials for Building Applications. Build. Environ. 2017, 114, 307-332. [CrossRef]

9. Aggrey-Smith, S.; Preko, K.; Owusu, F.W. Study of Thermal Properties of Some Selected Tropical Hard Wood Species. Int. J. Mater. Sci. Appl. 2016, 5, 143. [CrossRef]

10. Jankowska, A.; Kozokiewicz, P. Comparison of thermal properties of selected wood species intended to woodwork windows production. Ann. Wars. Univ. Life Sci. SGGW For. Wood Technol. 2014, 85, 101-105.

11. Tenwolde, A.; McNatt, J.D.; Krahn, L. Thermal Properties of Wood and Wood Panel Products for Use in Buildings; DOE/OR/21697-1; U.S. Department of Agriculture, Forest Service Forest Products Laboratory: Madison, WI, USA, 1988; p. 6059532. [CrossRef]

12. Maclean, J.D. Thermal conductivity of wood. Heat. Pip. Air Cond. 1941, 13, 380-391.

13. Çavuş, V.; Şahin, S.; Esteves, B.; Ayata, U. Determination of Thermal Conductivity Properties in Some Wood Species Obtained from Turkey. BioResources 2019, 14, 6709-6715.

14. Seo, J.; Kang, Y.; Kim, S. Wood Thermal Conductivity Database Construction for the Application of Building Energy Simulation. J. Korea Furnit. Soc. 2016, 27, 122-127.

15. Kim, S.; Yu, S.; Seo, J.; Kim, S. Thermal Performance of Wooden Building Envelope by Thermal Conductivity of Structural Members. J. Korean Wood Sci. Technol. 2013, 41. [CrossRef]

16. Vay, O.; De Borst, K.; Hansmann, C.; Teischinger, A.; Müller, U. Thermal Conductivity of Wood at Angles to the Principal Anatomical Directions. Wood Sci. Technol. 2015. [CrossRef]

17. Ahn, N.; Park, S. Comparative Analysis of Heat Transmittance of Timber Window Frames with Different Wood Species and Anatomical Direction. In Proceedings of the Autumn Annual Conference of the Korean Society of Wood Science Technology, Daegu, Korea, 24-25 September 2020.

18. Shin, M.-S.; Rhee, K.-N.; Yu, J.-Y.; Jung, G.-J. Determination of Equivalent Thermal Conductivity of Window Spacers in Consideration of Condensation Prevention and Energy Saving Performance. Energies 2017, 10, 717. [CrossRef]

19. Park, S.; Song, S.-Y. Evaluation of Alternatives for Improving the Thermal Resistance of Window Glazing Edges. Energies 2019, 12, 244. [CrossRef]

20. Hee, W.J.; Alghoul, M.A.; Bakhtyar, B.; Elayeb, O.; Shameri, M.A.; Alrubaih, M.S.; Sopian, K. The Role of Window Glazing on Daylighting and Energy Saving in Buildings. Renew. Sustain. Energy Rev. 2015, 42, 323-343. [CrossRef]

21. Gastines, M.; Correa, E.; Pattini, A. Window Frame Thermal Performance Simulation. Suitable Methods According to Climate and Technology. Revista de la Construcción 2018, 17, 112-122. [CrossRef]

22. Rogers, T.G. Considerations for the Condensation Resistance of Fenestration Assemblies. In Proceedings of the Building Enclosure Science \& Technology 2 Conference, Portland, OR, USA, 12-14 April 2010.

23. Sanders, H.; Lenz, J.; Sommer, P. Deconstructing the Window: Let's Forget about the Center of Glass. In Proceedings of the Building Enclosure Science \& Technology 5 Conference, Philadelphia, PA, USA, 15-18 April 2018.

24. Cha, J.; Seo, J.; Kim, S. Building Materials Thermal Conductivity Measurement and Correlation with Heat Flow Meter, Laser Flash Analysis, and TCi. J. Therm. Anal. Calorim. 2012, 109, 295-300. [CrossRef]

25. Seo, J.; Cha, J.; Kim, S.; Kim, S.; Huh, W. Development of the Thermal Performance of Wood-Flooring by Improving the Thermal Conductivity of Plywood. J. Biobased Mater. Bioenergy 2014, 8, 170-174. [CrossRef]

26. Jeon, J.-S.; Seo, J.-K.; Kim, S.-M. Suggestion of Thermal Environment Miniature for Evaluation of Heating Efficiency Based on Thermal Conductivity Measurement Method of Building Materials. J. Korean Wood Sci. Technol. 2011, 39, 269-280. [CrossRef] 
27. BC Reference Procedure and Tools for Using THERM to Determine Window Performance Values for Use with PHPP. Available online: https://www.fen-bc.org/resource_details.php?id_resource=3 (accessed on 8 October 2020).

28. NFRC. ANSI/NFRC 500-2020, Procedure for Determining Fenestration Product Condensation Index Ratings; National Fenetration Rating Council: Greenbelt, MD, USA, 2020.

29. Beall, F.C. Specific Heat of Wood: Further Research Required to Obtain Meaningful Data: [With List of Literature Cited]; U.S. Department of Agriculture, Forest Service, Forest Products Laboratory: Madison, WI, USA, 1968.

30. ISO. ISO 13061-1:2014, Physical and Mechanical Properties of Wood-Test Methods for Small Clear Wood Specimens-Part 1: Determination of Moisture Content for Physical and Mechanical Tests; International Organization for Strandardization: Geneva, Switzerland, 2014.

31. NFRC. ANSI/NFRC 100-2020, Procedure for Determining Fenestration Product U-factors; National Fenetration Rating Council: Greenbelt, MD, USA, 2017.

32. ISO. ISO 10077-2:2017, Thermal Performance of Windows, Door, and Shutters-Calculation of Thermal Transmittance-Part 2: Numerical Method for Frames; International Organization for Strandardization: Geneva, Switzerland, 2017.

33. Wright, J.L. Using a 4th Surface Low-e Coating on Windows in a Cold Climate: Background, Observations, and Practical Strategies_White Paper. Available online: http://www.solarme.uwaterloo.ca/DownloadPDFs/ FSWhitePaper_final.pdf (accessed on 19 October 2020).

Publisher's Note: MDPI stays neutral with regard to jurisdictional claims in published maps and institutional affiliations.

(C) 2020 by the authors. Licensee MDPI, Basel, Switzerland. This article is an open access article distributed under the terms and conditions of the Creative Commons Attribution (CC BY) license (http://creativecommons.org/licenses/by/4.0/). 